\title{
ESTOQUE DE CARBONO EM SISTEMAS AGROSSILVOPASTORIL, PASTAGEM E EUCALIPTO SOB CULTIVO CONVENCIONAL NA REGIÃO NOROESTE DO ESTADO DE MINAS GERAIS ${ }^{1}$
}

\author{
Carbon stock in agricultural-forestry-pasture, planted pasture, and eucalyptus \\ systems under conventional tillage in the northwestern region of the Minas Gerais State
}

\author{
Cláudia Milene Nascente das Neves², Marx Leandro Naves Silva ${ }^{3}$, \\ Nilton Curi ${ }^{3}$, Renato Luiz Grisi Macedo ${ }^{4}$, Alessandra Mayumi Tokura ${ }^{5}$
}

\section{RESUMO}

Conduziu-se este estudo com o objetivo de verificar as alterações nos teores e no estoque de carbono orgânico em sistemas agrossilvopastoril, pastagem cultivada e reflorestamento de eucalipto, no noroeste do Estado de Minas Gerais. O solo estudado foi um Latossolo Vermelho distrófico típico. As amostragens de solo foram efetuadas em três repetições, nas profundidades de 0-5, 5-20 e 20-40 cm. Os sistemas foram selecionados segundo o histórico de uso, a saber: cerrado nativo (CN - testemunha); eucalipto + arroz (EA - ano zero do sistema agrossilvopastoril); eucalipto + soja (ES - ano um do sistema agrossilvopastoril); eucalipto + pastagem (EP - ano dois do sistema agrossilvopastoril); eucalipto + pastagem + gado (EPG - ano três do sistema agrossilvopastoril); pastagem convencional (PC) e eucalipto convencional (EC). Houve diferença significativa nos teores e no estoque de carbono dos sistemas avaliados em relação ao cerrado nativo. De modo geral, os sistemas estão desempenhando um papel de emissores de $\mathrm{C}-\mathrm{CO}_{2}$, quando comparados com o CN, em que os vários revolvimentos para o preparo do solo estão acelerando o processo de oxidação e perda de carbono orgânico. No sistema agrossilvopastoril, foi observada uma tendência de aumento do estoque do carbono com o passar dos anos, demonstrando a eficiência do sistema em manter ou até mesmo aumentar o estoque de carbono orgânico ao longo dos anos.

Termos para indexação: Qualidade do solo, estoque de carbono, sistema agrossilvopastoril, cerrado.

\begin{abstract}
The objective of this study was to verify the alterations in the amounts and storage of organic carbon in agricultural-forestry-pasture, planted pasture and eucalyptus reforestation systems in the northwestern part of the Minas Gerais State. The studied soil was a typical dystrophic Red Latosol. The soil samplings were performed in three replicates at the depths of 0-5, 5-20 and 20-40 cm. The systems were selected according to the historical use, namely, native cerrado (referential), eucalyptus + rice (year zero of the agricultural-forestry-pasture system), eucalyptus + soybeans (year one of the agricultural-forestry-pasture system); eucalyptus + pasture (year two of the agricultural-forestry-pasture system), eucalyptus + pasture + cattle raising (year three of the agricultural-forestry-pasture system), conventional pasture and conventional eucalyptus. There was significant difference in the amounts and stock of carbon of the evaluated systems in relation to the native cerrado. In general, the systems are functioning as $\mathrm{C}-\mathrm{CO}_{2}$ emitter when compared with the native cerrado, where the various tillage operations are accelerating the oxidation process and loss of organic carbon. It was observed a trend of increment of the carbon stock as time goes by in the agricultural-forestry-pasture systems, demonstrating the efficiency of this system in maintaining or even increasing the organic carbon stock along the years.
\end{abstract}

Index terms: Soil quality, carbon stock, agricultural-forestry-pasture system, cerrado.

(Recebido para publicação em 13 de janeiro de 2003 e aprovado em 20 de setembro de 2004)

\section{INTRODUÇÃO}

A transformação de sistemas naturais em áreas agrícolas constitui, nas regiões tropicais, uma importante causa do aumento da concentração de $\mathrm{CO}_{2}$ atmosférico, o que está relacionado a alterações climáticas globais. Estima-se que $45 \%$ da vegetação original do cerrado brasileiro foram devastados, para ceder lugar a áreas de

1. Parte da dissertação apresentada à Universidade Federal de Lavras/UFLA - Caixa Postal 3037 - 37200-000 - Lavras, MG, pelo primeiro autor, para a obtenção do título de Mestre em Agronomia, área de concentração Solos e Nutrição de Plantas. Trabalho apresentado na XIV Reunião Brasileira de Manejo e Conservação do Solo e da Água, no período de 21 a 26 de julho de 2002, Cuiabá MT.

2. Zootecnista, MSc, Departamento de Ciência do Solo/UFLA. claudia@ufla.br

3. Engenheiros Agrônomos, Drs., Professores do Departamento de Ciência do Solo/UFLA. Bolsista do CNPq, marx@ufla.br; niltcuri@ufla.br

4. Engenheiro Agrônomo, Dr., Professor do Departamento de Engenharia Florestal/UFLA. regrisi@ufla.br

5. Engenheiro Agrônomo, Dra., Departamento de Ciência do Solo/UFLA. amtokura@zipmail.com.br 
pastagem cultivada, culturas anuais e reflorestamento. Em solos sob vegetação natural, o balanço entre as adições e perdas de carbono leva a um estado de equilíbrio dinâmico, no qual praticamente não existe variação no teor de carbono orgânico com o tempo (BAYER e MIELNICZUK, 1999). No entanto, na conversão da vegetação natural em áreas agrícolas e florestais, verifica-se, em geral, nas regiões tropicais, uma rápida perda de carbono orgânico do solo, em decorrência da combinação entre calor e umidade, que facilita a decomposição, e também, o constante revolvimento do solo contribui para acelerar a oxidação do carbono orgânico (CASTRO FILHO et al., 1991).

Estudos a respeito do carbono orgânico do solo sob diferentes sistemas fornecem subsídios importantes para a avaliação da qualidade do solo. Existe interesse cada vez maior na identificação dos sistemas de manejo de culturas e pastagens que promovam a melhoria do estoque de carbono no solo (FREITAS et al., 2000). Nos últimos anos, tem sido ressaltada a contribuição do plantio direto na diminuição da emissão de $\mathrm{CO}_{2}$ para a atmosfera (BURLE et al., 1997; BAYER et al., 2000a,b; D’ANDRÉA, 2001; SILVA, 2001). Fortin et al. (1996) determinaram uma redução da emissão de carbono na ordem de 2,50 $\mathrm{Mg} \mathrm{CO}_{2} \mathrm{ha}^{-1}$ ano $^{-1}$ no plantio direto, comparativamente ao preparo convencional. Em estudos desenvolvidos por Freixo et al. (2002), em diversos sistemas de cultivos, em Latossolo na região do cerrado, concluiu-se que o decréscimo de estoque de carbono orgânico foi menor no plantio direto (20 a $30 \%$ de $0-5 \mathrm{~cm}$ ) e maior nos sistemas convencionais ( $47 \%$ de $0-5 \mathrm{~cm}$ ).

O menor teor do carbono orgânico estocado no solo está diretamente relacionado com o aumento da emissão de $\mathrm{CO}_{2}$ para a atmosfera, que pode estar aumentando o efeito estufa. Isso porque o gás carbônico é um dos principais gases causadores desse efeito e cujas emissões no mundo cresceram vertiginosamente nos últimos 40 anos (ROCHA, 2000). Segundo o mesmo autor, comparando-se a outros países, o Brasil tem todas as condições de assumir uma posição privilegiada junto aos movimentos que buscam reverter o processo de mudança climática global, tanto do ponto de vista da redução das emissões como em projetos de seqüestro de carbono por meio dos sistemas de plantio direto, reflorestamentos, agroflorestais e agrossilvopastoris, ou seja, sistemas que visam ao estoque e conservação do carbono.

Assim, objetivou-se com este estudo verificar alterações nos teores e no estoque de carbono orgânico, em decorrência da adoção dos sistemas agrossilvopastoril, pastagem cultivada e reflorestamento de eucalipto em área originalmente sob cerrado nativo, num Latossolo Vermelho distrófico típico da região noroeste do Estado de Minas Gerais.

\section{MATERIAL E MÉTODOS}

A área de estudo está localizada entre os municípios de Vazante e Paracatu, na fazenda experimental Bom Sucesso, de propriedade da Companhia Mineira de Metais (CMM), localizada na latitude sul $17^{\circ} 33^{\prime}$ e longitude oeste $46^{\circ} 42^{\prime}$, no noroeste do Estado de Minas Gerais. O clima da região é do tipo subtropical úmido, com temperatura média máxima de $32^{\circ} \mathrm{C}$ e mínima de $16^{\circ} \mathrm{C}$. As precipitações médias anuais variam de 1.300 a $1.800 \mathrm{~mm}$. O solo estudado foi classificado como Latossolo Vermelho distrófico típico (LVd).

Os sistemas foram selecionados segundo o histórico de uso, a saber: (1) $\mathrm{CN}$ - cerrado nativo, considerado referência; (2) EA - eucalipto + arroz, primeira sucessão do sistema agrossilvopastoril, plantada após o desmatamento da vegetação nativa de cerrado e das operações do preparo do solo, com aração e gradagem, correção e fertilização com NPK. O arroz foi semeado em consórcio com mudas de eucalipto; (3) ES - eucalipto + soja, ano um do sistema, semeadura da soja em substituição ao arroz, na entrelinha o eucalipto, após o preparo do solo com aração e gradagem, seguido da adubação com NPK; (4) EP - eucalipto + pastagem, ano dois do sistema, com pastagem de Brachiaria brizantha, manejada para a engorda do gado bovino de corte. A semeadura da forrageira ocorreu após o preparo do solo e fertilização com uma mistura de fosfato natural e superfosfato simples; (5) EPG - eucalipto + pastagem + gado bovino, ano três do sistema agrossilvopastorial, introdução do pastejo. Os novilhos foram adquiridos a cada dois anos, considerando um prazo necessário para engorda. Assim, a cada dois anos, os animais são comercializados e substituídos por outros para dar início a um novo ciclo de engorda.

A título de comparação, selecionou-se uma área de pastagem plantada de Brachiaria brizantha de longo uso, sob pastejo contínuo de gado bovino em regime extensivo e sem manejo de fertilidade nos últimos 10 anos. Também selecionou-se uma área de plantio de eucalipto no sistema convencional no espaçamento de 2,0 x 3,0 m, sem manejo de fertilidade e tratos silviculturais nos últimos 10 anos.

As amostragens de solo foram feitas em minitrincheiras no ano de 2001, durante o mês de maio, em três profundidades (0-5, 5-20 e 20-40 cm), na entrelinha dos plantios. Em cada profundidade, para todos os sistemas, foram retiradas seis amostras simples, cada uma constituindo uma amostra composta em triplica- 
ta, que constituiu uma repetição, em que cada parcela delimitada na área de cultivo media 200 m² $^{2}(10$ x 20 $\mathrm{m})$. As amostras foram acondicionadas em sacos plásticos, sendo protegidas da luz e mantidas em caixas térmicas, antes de serem transportadas para o laboratório, onde foram secas ao ar e passadas em peneira de 2,0 mm (terra fina).

Procedeu-se à análise granulométrica pelo método da pipeta (DAY, 1965), após dispersão da amostra com NaOH $1 \mathrm{~mol} \mathrm{~L}^{-1}$ e agitação rápida (6.000 rpm) por 15 minutos. Os valores obtidos são apresentados na Tabela 1. $\mathrm{O}$ pH em água e os componentes do complexo sortivo foram determinados de acordo com Embrapa (1997) e encontra-se na Tabela 2.

TABELA 1 - Granulometria do Latossolo Vermelho distrófico típico nas três profundidades e sob sistemas de manejo estudados.

\begin{tabular}{|c|c|c|c|}
\hline \multirow{2}{*}{ Sistema } & Areia & Silte & Argila \\
\hline & \multicolumn{3}{|c|}{------------------g kg ${ }^{-1}-------------$} \\
\hline & \multicolumn{3}{|c|}{$0-5 \mathrm{~cm}$} \\
\hline $\mathrm{CN}$ & 177 & 141 & 681 \\
\hline EA & 145 & 151 & 704 \\
\hline ES & 89 & 201 & 710 \\
\hline EP & 116 & 121 & 762 \\
\hline EPG & 209 & 160 & 630 \\
\hline PC & 72 & 168 & 759 \\
\hline \multirow[t]{2}{*}{$\mathrm{EC}$} & 191 & 74 & 733 \\
\hline & \multicolumn{3}{|c|}{$5-20 \mathrm{~cm}$} \\
\hline $\mathrm{CN}$ & 162 & 176 & 661 \\
\hline EA & 140 & 172 & 687 \\
\hline ES & 109 & 172 & 718 \\
\hline EP & 121 & 157 & 721 \\
\hline EPG & 200 & 137 & 662 \\
\hline PC & 70 & 202 & 707 \\
\hline \multirow[t]{2}{*}{$\mathrm{EC}$} & 197 & 114 & 688 \\
\hline & \multicolumn{3}{|c|}{$20-40 \mathrm{~cm}$} \\
\hline $\mathrm{CN}$ & 152 & 133 & 715 \\
\hline EA & 126 & 128 & 727 \\
\hline ES & 93 & 129 & 777 \\
\hline EP & 94 & 105 & 802 \\
\hline EPG & 188 & 143 & 668 \\
\hline PC & 64 & 220 & 716 \\
\hline EC & 184 & 112 & 704 \\
\hline
\end{tabular}

Avaliou-se o carbono orgânico total (CO) por oxidação a quente com dicromato de potássio e titulação com sulfato ferroso amoniacal, segundo a metodologia modificada de Walkley e Black (1934). O carbono acumulado em cada camada de solo estudada (estoque de carbono orgânico) foi calculado utilizando-se a expressão (FREIXO et al., 2002):

$$
E s t C=\frac{\text { COtotal } * D s * e}{10}
$$

Em que:

EstC = estoque de carbono orgânico na camada estudada $\left(\mathrm{Mg} \mathrm{ha}^{-1}\right)$;

CO total = carbono orgânico total $\left(\mathrm{g} \mathrm{kg}^{-1}\right)$;

Ds = densidade do solo da camada estudada $\left(\mathrm{kg} \mathrm{dm}^{-3}\right)$;

$\mathrm{e}=$ espessura da camada estudada $(\mathrm{cm})$.

Para verificar a tendência em acumular ou perder carbono orgânico em relação ao sistema de referência, foi calculada a variação do estoque de carbono em relação ao cerrado nativo ( $\triangle \mathrm{EstC}, \mathrm{Mg} \mathrm{ha}^{-1}$ ), pela diferença entre os valores médios do estoque de carbono nesse sistema e em cada um dos demais, nas profundidades estudadas.

O delineamento experimental utilizado foi o inteiramente casualisado (DIC), com estrutura em faixas devido às profundidades de amostragem. Para a verificação dos pressupostos da análise de variância, foram utilizados os procedimentos "Univariate” e "General Linear Models” (GLM) do pacote estatístico SAS (SAS INSTITUTE, 1985). Os valores de carbono orgânico total foram transformados com o uso da função $\mathrm{y}=\log \mathrm{x}$ (logaritmo base 10) para as análises de variância. Na apresentação das tabelas, foram utilizados os dados brutos (nãotransformados). As comparações múltiplas de médias foram feitas pelo teste de Scott e Knott a 5\% de probabilidade, utilizando o programa SISVAR (FERREIRA, 2000).

$\mathrm{O}$ modelo usado no delineamento foi: $\mathrm{Y} i j=\mathrm{m}+$ $\mathrm{Si}+$ Erro (sistema) $+\mathrm{Pj}+\mathrm{SP} i j+$ Erro (geral), em que Yij: é o valor de cada observação; m: média da observação no sistema $i$ e profundidade $j$; Si: efeito do sistema $i$; Erro (sistema): erro devido ao efeito da repetição dentro do sistema $i$; Pj: efeito da profundidade $j$; SP $i j$ : efeito da interação entre o sistema $i$ e a profundidade $j$; Erro (geral): resíduo geral.

\section{RESULTADOS E DISCUSSÃO}

Os valores de $\mathrm{pH}$ e bases trocáveis são bastante variáveis (Tabela 2), pois refletem o sistema de manejo adotado, além da profundidade avaliada. Observa-se, de modo geral, que o solo sob cerrado (CN) apresentou valor de $\mathrm{pH}$ menor em relação aos outros sistemas de manejo, para todas as profundidades avaliadas. Pode-se observar valores nulos ou quase nulos de alumínio trocá- 
Estoque de carbono em sistemas agrossilvopastoril, pastagem e eucalipto sob...

1041

vel nos solos manejados. Com relação aos cátions básicos trocáveis, a maioria dos sistemas de manejo, em relação ao cerrado nativo, apresentou valores superiores de cálcio, magnésio e de potássio, nas três profundidades, como conseqüência das adubações e calagens realizadas.

É sabido que a matéria orgânica é um fonte de fósforo, por meio da decomposição e mineralização (TOKURA et al., 2002). O CN apresentou teor mais alto de $\mathrm{P}$ que os demais sistemas de manejo, com exceção do EP, devido possivelmente à utilização da mistura de fos- fato natural com superfosfato simples, superestimando o valor de P disponível determinado pelo extrator. Embora tenha havido a adubação fosfatada em todas as áreas manejadas, essas apresentaram menores teores de $\mathrm{P}$ em relação ao cerrado, em virtude do revolvimento do solo, ocasionando rupturas dos agregados, procedimento que pode expor novos sítios de adsorção de $\mathrm{P}$, reduzindo o $\mathrm{P}$ disponível, assim como a maior oxidação da matéria orgânica. Outro fator, entretanto, de menor intensidade é a exportação do P com o cultivo.

TABELA 2 - Atributos químicos em Latossolo Vermelho distrófico típico em diferentes profundidades e sistemas de manejo.

\begin{tabular}{|c|c|c|c|c|c|c|c|c|c|c|}
\hline \multirow{2}{*}{ Sistema } & \multirow{2}{*}{ Profundidade } & pH & $\mathbf{P}$ & $\mathbf{K}$ & Ca & Mg & Al & SB & $\mathbf{V}$ & $\mathbf{m}$ \\
\hline & & & \multicolumn{2}{|c|}{$---\left(\mathrm{mg} \mathrm{dm}^{-3}\right)---$} & \multicolumn{4}{|c|}{ - $\left(\mathrm{cmol}_{\mathrm{c}} \mathrm{dm}^{-3}\right)$} & \multicolumn{2}{|c|}{----- (\%) ----- } \\
\hline & $0-5$ & 4,8 & 1,00 & 76,67 & 0,57 & 0,17 & 1,50 & 0,93 & 11,30 & 62,00 \\
\hline \multirow[t]{3}{*}{$\mathrm{CN}$} & $5-20$ & 4,9 & 0,53 & 53,00 & 0,40 & 0,17 & 1,33 & 0,70 & 9,77 & 65,33 \\
\hline & $20-40$ & 4,7 & 1,40 & 41,67 & 0,43 & 0,20 & 1,27 & 0,73 & 12,40 & 62,33 \\
\hline & $0-5$ & 5,2 & 0,37 & 40,67 & 1,40 & 1,33 & 0,20 & 2,83 & 44,77 & 8,00 \\
\hline \multirow[t]{3}{*}{ EA } & $5-20$ & 4,9 & 0,30 & 24,67 & 0,77 & 0,23 & 0,50 & 1,10 & 20,53 & 33,33 \\
\hline & $20-40$ & 4,9 & 0,10 & 16,33 & 0,43 & 0,17 & 0,47 & 0,63 & 15,20 & 42,33 \\
\hline & $0-5$ & 5,7 & 0,73 & 52,33 & 2,57 & 2,43 & 0,00 & 5,13 & 67,77 & 0,00 \\
\hline \multirow[t]{3}{*}{ ES } & $5-20$ & 5,0 & 0,47 & 30,33 & 0,67 & 0,20 & 0,77 & 0,97 & 18,53 & 44,67 \\
\hline & $20-40$ & 4,9 & 0,27 & 23,00 & 0,43 & 0,17 & 0,53 & 0,63 & 15,90 & 45,33 \\
\hline & $0-5$ & 5,2 & 4,83 & 40,67 & 1,47 & 1,30 & 0,33 & 2,87 & 41,37 & 11,33 \\
\hline \multirow[t]{3}{*}{ EP } & $5-20$ & 5,2 & 1,93 & 23,67 & 0,87 & 0,47 & 0,87 & 1,43 & 22,90 & 40,33 \\
\hline & $20-40$ & 5,1 & 0,30 & 18,00 & 0,43 & 0,20 & 1,07 & 0,67 & 12,73 & 61,00 \\
\hline & $0-5$ & 5,5 & 0,60 & 42,33 & 1,47 & 1,40 & 0,17 & 3,00 & 46,13 & 5,33 \\
\hline \multirow[t]{3}{*}{ EPG } & $5-20$ & 5,2 & 0,20 & 17,00 & 0,77 & 0,20 & 0,73 & 1,00 & 20,10 & 41,00 \\
\hline & $20-40$ & 5,1 & 0,20 & 14,67 & 0,53 & 0,17 & 0,73 & 0,70 & 15,97 & 50,67 \\
\hline & $0-5$ & 5,5 & 0,80 & 157,67 & 1,03 & 0,80 & 0,30 & 2,23 & 36,60 & 12,00 \\
\hline \multirow[t]{3}{*}{ PC } & $5-20$ & 5,8 & 0,37 & 41,33 & 0,73 & 0,27 & 0,67 & 1,13 & 20,53 & 38,00 \\
\hline & $20-40$ & 5,7 & 0,20 & 22,33 & 0,50 & 0,17 & 0,67 & 0,77 & 14,80 & 47,00 \\
\hline & $0-5$ & 4,9 & 2,10 & 62,33 & 0,77 & 0,20 & 1,40 & 1,13 & 14,30 & 55,33 \\
\hline \multirow[t]{2}{*}{ EC } & $5-20$ & 5,0 & 1,10 & 29,33 & 0,50 & 0,20 & 1,43 & 0,80 & 11,77 & 65,00 \\
\hline & $20-40$ & 5,0 & 0,60 & 23,67 & 0,40 & 0,20 & 1,33 & 0,70 & 12,40 & 67,00 \\
\hline
\end{tabular}


Os teores de carbono orgânico total (CO) no sistema agrossilvopastoril diferiram entre o cerrado nativo, do ponto de vista estatístico, nas três profundidades de amostragem (Tabela 3).

TABELA 3 - Carbono Orgânico Total em Latossolo Vermelho Distrófico Típico para sete sistemas em três profundidades.

\begin{tabular}{cccc}
\hline \multirow{2}{*}{ Sistemas } & \multicolumn{3}{c}{ Profundidades (cm) } \\
\cline { 2 - 4 } & $0-5$ & $5-20$ & $20-40$ \\
\hline & --------- CO $\left(\mathrm{g} \mathrm{kg}^{-1}\right)$ & ---------- \\
CN & 22,6 a A & 15,2 a B & 11,9 a C \\
EA & 13,5 c A & 11,4 c B & 8,5 b C \\
ES & 15,2 c A & 11,6 c B & 8,3 b C \\
EP & 14,8 c A & 12,5 c B & 9,1 b C \\
EPG & 14,6 c A & 10,6 c B & 8,9 b B \\
PC & 15,4 c A & 14,5 a A & 11,2 a B \\
EC & 19,7 b A & 13,3 b B & 11,2 a C \\
\hline CV sistema & (\%) & 10,23 & \\
CV geral & (\%) & 6,80 & \\
\hline
\end{tabular}

Médias seguidas pela mesma letra, minúscula na coluna e maiúscula na linha, não diferem estatisticamente entre si pelo teste de Scott-Knott a $5 \%$ de probabilidade.

Os teores de carbono orgânico foram influenciados pela profundidade em todos os sistemas, sendo maiores na superfície $(0-5 \mathrm{~cm})$. Tanto no solo sob cerrado, como no sistema agrossilvopastoril, na pastagem convencional e no eucalipto convencional, houve uma tendência geral de diminuição nos teores de carbono totais com o aumento da profundidade, visto que a camada superficial do solo é a zona onde a deposição de materiais orgânicos ocorre com maior intensidade. Entretanto, a perturbação antrópica do sistema estável (CN) causou mais perdas do que ganhos de carbono, principalmente pelo preparo do solo, especialmente pela intensidade do revolvimento, aumento da oxidação de compostos orgânicos, ruptura mecânica dos agregados e exposição da superfície do solo ao impacto das gotas de chuva.

Embora tenha ocorrido uma queda do carbono orgânico após o desmatamento do cerrado para a im- plantação do sistema agrossilvopastorial, principalmente nos sistemas EA e ES, observa-se já no ano seguinte (EP) uma tendência de aumento do teor de carbono. Porém, uma nova queda foi observada no sistema EPG, sendo essa redução relacionada ao pastejo com a introdução do gado, com diminuição da biomassa verde, associada ao aumento da compactação (observação de campo), contribuindo para a redução do carbono orgânico. Resultados semelhantes também foram encontrados por Freixo et al. (2002), com redução dos teores de $\mathrm{CO}$ em profundidade na região dos cerrados.

Com relação aos sistemas, o CN apresentou maiores valores de carbono orgânico total em todas as profundidades, e isso pode ser devido à queda de folhas e material vegetal na superfície e também à ausência de revolvimento, que contribui para a manutenção de CO no sistema (CASTRO FILHO et al., 1991). Em seguida vieram os sistemas PC e EC, pelo fato de serem sistemas mais estabilizados, que estão instalados há vários anos (Tabela 3), não havendo interferência de manejo que altere esse equilíbrio, ocorrendo, conseqüentemente, um maior acúmulo de matéria orgânica. Exceto na profundidade de 0 - $5 \mathrm{~cm}$ do sistema PC, que se iguala estatisticamente com os sistemas agrossilvopastorial, esse efeito pode ser devido ao grau de degradação em que a pastagem se encontrava, e segundo observações de campo (NEVES, 2002), havia sítios de encrostamento superficial, erosão laminar, grande incidência de plantas invasoras e pragas.

Já nas profundidades de 5 - 20 e 20-40 cm, o teor de $\mathrm{CO}$ iguala-se estatisticamente com o teor do $\mathrm{CN}$, o que pode ser devido à alta densidade do sistema radicular da gramínea, o que está de acordo com Greenland (1971). Segundo esse autor, a recuperação dos teores de CO pode ser obtida mediante a implantação de pastagem, ou, no caso de sistemas de produção intensivos, mediante a redução do revolvimento do solo e da adoção de um sistema de rotação de culturas com a inclusão de espécies de alta produção de fitomassa (BAYER e MIELNICZUK, 1997). Desse modo, a adoção de sistema de uso e manejo do solo deve levar em consideração, entre outros aspectos, o seu efeito sobre os teores de CO.

Os sistemas de manejo usados na exploração agrossilvopastorial, além do seu efeito sobre os teores de $\mathrm{CO}$, afetaram a quantidade de $\mathrm{CO}_{2}$ liberada do solo para a atmosfera.

O estoque de carbono para os diferentes sistemas de manejo nas três profundidades é apresentado na Tabela 4. Houve interação significativa $(P \leq 0,05)$ entre sistemas de manejo e profundidades. Para o cálculo do estoque de 
carbono, considerou-se a espessura da camada em estudo; por isso, não foram avaliados os valores em relação às diferentes profundidades, já que essas possuem diferentes espessuras. Assim, foram avaliados os valores de estoque de carbono em relação aos sistemas (NEVES, 2002).

Os maiores valores de estoque de carbono foram observados para os sistemas CN e EC, seguido pelo PC, além da manutenção dos maiores valores em profundidade. Segundo Freitas et al. (2000) ressaltam o papel da argila na estruturação do solo e em proteger a matéria orgânica do solo contra a decomposição, em sistemas que apresentam ausência de revolvimento do solo, tendo em vista que o solo estudado apresenta textura muito argilosa (Tabela 1). Esses resultados estão em consonância com observações de Freixo et al. (2002), que trabalharam também com Latossolo sob cerrado.

No sistema agrossilvopastoril, observa-se uma queda acentuada nos primeiros anos (EA e ES), que são os sistemas mais jovens, em que a taxa de adição de resíduos orgânicos é baixa, havendo revolvimento do solo em relação ao sistema em equilíbrio $(\mathrm{CN})$, com uma tendência de recuperação nos próximos anos (EP e EPG).

TABELA 4 - Estoque de carbono em Latossolo Vermelho distrófico típico para sete sistemas em três profundidades.

\begin{tabular}{|c|c|c|c|}
\hline \multirow{2}{*}{ Sistemas } & \multicolumn{3}{|c|}{ Profundidades (cm) } \\
\hline & $0-5$ & $5-20$ & $20-40$ \\
\hline & \multicolumn{3}{|c|}{----------Est C $\left(\mathrm{Mg} \mathrm{ha}^{-1}\right)----$} \\
\hline CN & $10,5 \mathrm{a}$ & 24,6 a & $27,3 \mathrm{a}$ \\
\hline EA & $6,8 \mathrm{~b}$ & $18,2 \mathrm{c}$ & $17,0 \mathrm{~d}$ \\
\hline ES & $7,3 \mathrm{~b}$ & $17,7 \mathrm{c}$ & $16,1 \mathrm{~d}$ \\
\hline EP & $7,6 \mathrm{~b}$ & $21,7 \mathrm{~b}$ & $18,6 \mathrm{c}$ \\
\hline EPG & $8,7 \mathrm{~b}$ & $17,9 \mathrm{c}$ & $18,8 \mathrm{c}$ \\
\hline PC & $8,4 \mathrm{~b}$ & $21,6 \mathrm{~b}$ & $22,2 \mathrm{~b}$ \\
\hline $\mathrm{EC}$ & $11,6 \mathrm{a}$ & $22,9 \mathrm{~b}$ & 25,5 a \\
\hline CV sistema & $(\%)$ & 11,84 & \\
\hline CV geral & $(\%)$ & 8,03 & \\
\hline
\end{tabular}

Médias seguidas pela mesma letra na coluna não diferem estatisticamente entre si pelo teste de ScottKnott a 5\% de probabilidade.

O EstC acumulado na camada de 0-20 cm aproximou-se daquele apresentado por Corozza et al. (1999) somente para o cerrado nativo (35,1 $77 \mathrm{Mg} \mathrm{ha}^{-1}$ neste trabalho contra $39,77 \mathrm{Mg} \mathrm{ha}^{-1}$ ). Esses autores encontraram, em termos absolutos, um menor distanciamento dos obtidos no presente estudo. Para os demais sistemas de manejo, os resultados obtidos neste trabalho foram marcadamente diferentes daqueles reportados pelo mesmo autor.

Analisando separadamente o EstC por profundidade (Tabela 4), nota-se que existiram grandes diferenças entre os sistemas de manejo - o que mais se aproximou do CN foi o EC, seguido do PC, refletindo perdas, ainda que pequenas, de carbono orgânico do solo em relação ao sistema de referência (CN).

Em virtude de haver uma tendência de maiores valores de quantidades de carbono presentes nas três profundidades estarem nos sistemas menos perturbados, como no EC e PC, espera-se que, com a adoção do plantio direto nos primeiros anos (EA e ES), ocorra um maior incremento na recuperação dos teores originais de estoque de carbono orgânico (CASTRO FILHO et al., 1991; FORTIN et al., 1996; BAYER et al., 2000a). Segundo Burle et al. (1997) e Bayer et al. (2000b), o plantio direto ou sistemas de cultivo com grande aporte de resíduos orgânicos de longa duração resulta num aumento dos estoques de carbono orgânico do solo.

Nesse sentido, mais informativa que os valores absolutos de EstC é a variação dos mesmos em relação ao cerrado nativo ( $\triangle$ EstC) (Figura 1 ). Esse parâmetro permite avaliar se o solo está armazenando ou emitindo C-CO $\mathrm{CO}_{2}$ para atmosfera (FORTIN et al., 1996; BAYER et al., 2000; ROCHA, 2000); assim, foi constatado que o CN está desempenhando um papel de seqüestrador (armazenador) de carbono, pois o $\mathrm{CN}$ apresentou valores de estoque de carbono superior aos demais sistemas.

Analisando-se as variações do estoque de carbono nos sistemas em relação ao CN (Figura 1), foi verificado que quase todos os sistemas tenderam a apresentar valores negativos, isto é, os sistemas estão desempenhando um papel de emissores de $\mathrm{C}-\mathrm{CO}_{2}$, quando comparados com o CN, exceto o sistema EC, possivelmente devido à ausência de revolvimento do solo por vários anos (10 anos) e acúmulo de serrapilheira. Levando-se em consideração que o tempo de implantação do sistema agrossilvopastoril (EA, ES e EP) contribuiu para aumentar o EstC em relação ao cerrado nativo, acredita-se que a tendência do sistema agrossilvopastoril é ter valores positivos de estoque em relação ao cerrado nativo, visto que em todas as profundidades foi observada uma tendência em diminuir a variação estoque do carbono com a estabilização do sistema. Com isso, torna-se necessário um cuidado no manejo dos sistemas, em que os vários revolvimentos para o preparo do solo estão acelerando o processo de oxidação e perda de carbono orgânico, o que evidencia a importância da adequação dos sistemas de manejo na redução da emissão de $\mathrm{CO}_{2}$ para a atmosfera. 
$0-5 \mathrm{~cm}$

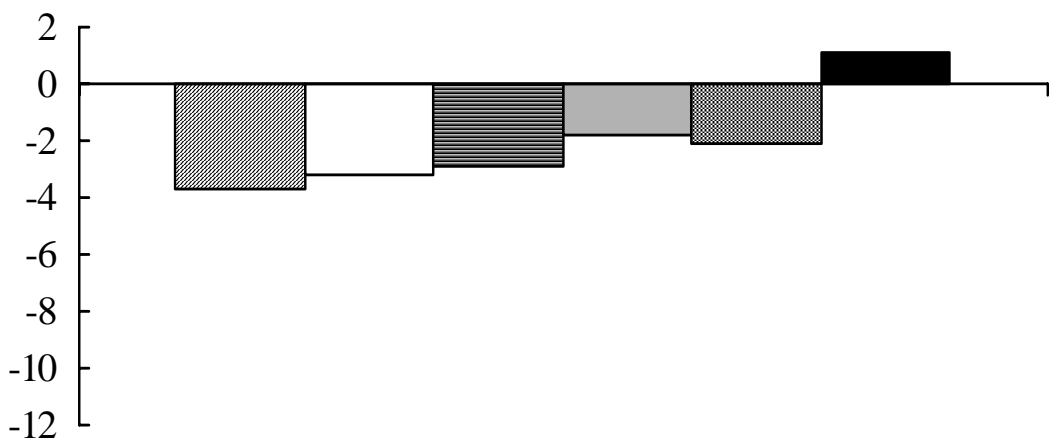

$5-20 \mathrm{~cm}$

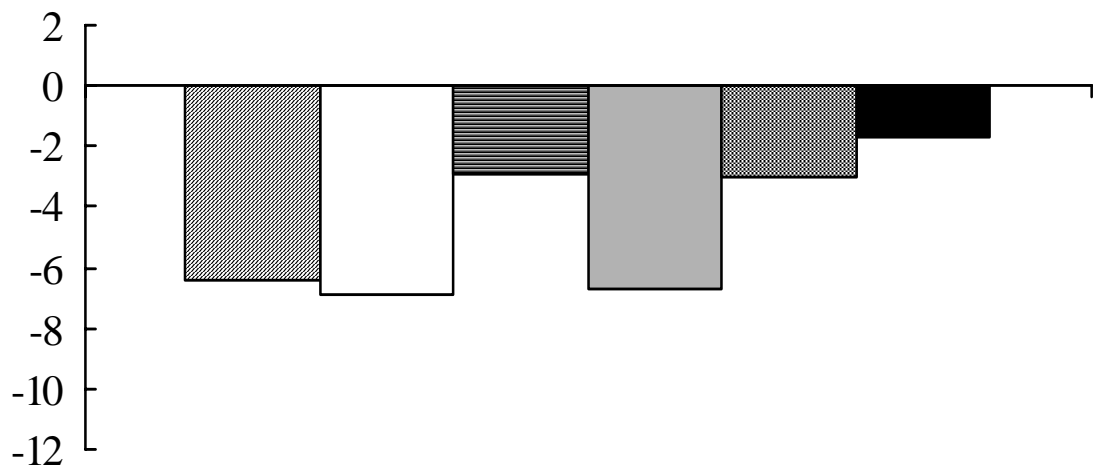

$20-40 \mathrm{~cm}$

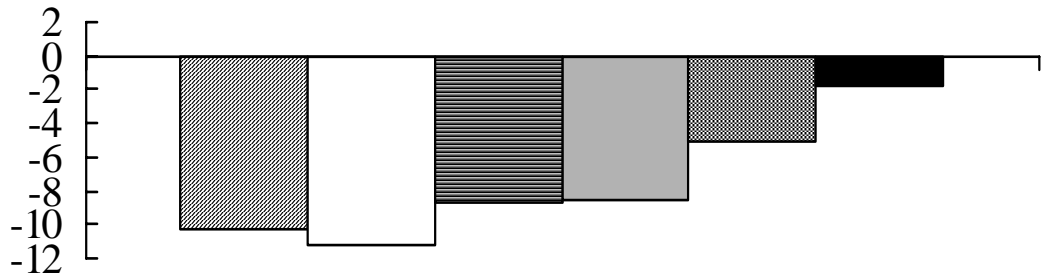

首EA $\square$ ES 目EP $\square$ EPG $\square$ PC $\square$ EC

FIGURA 1 - Variação do estoque de carbono nos sistemas em relação ao cerrado nativo (CN) em Latossolo Vermelho distrófico típico. 
Dessa forma, o manejo adequado para conservação do solo e produtividade das culturas deve ter como premissa a utilização de métodos de preparo mínimo ou nenhum revolvimento do solo e sistemas de rotação/sucessão de culturas que incluam plantas com alta produção de resíduos vegetais.

\section{CONCLUSÕES}

Os valores de $\mathrm{pH}$, bases trocáveis e $\mathrm{P}$ foram variáveis, refletindo o efeito do sistema de manejo adotado.

Houve diferença significativa no estoque de carbono dos sistemas avaliados em relação ao cerrado nativo. $\mathrm{O}$ sistema agrossilvopastoril está desempenhando um papel de emissor de $\mathrm{C}-\mathrm{CO}_{2}$, quando comparado com o $\mathrm{CN}$.

Do cerrado nativo para o eucalipto em consórcio com o arroz (EA), o estoque de carbono sofreu uma considerável redução. Entretanto, com a evolução do sistema agrossilvopastoril, houve uma tendência de recuperação do estoque de carbono original.

O estoque de carbono orgânico mostrou ser um atributo promissor para avaliação da qualidade do solo.

\section{REFERÊNCIAS BIBLIOGRÁFICAS}

BAYER, C.; MIELNICZUK, J. características químicas do solo afetadas por métodos de preparo e sistemas de culturas. Revista Brasileira de Ciência do Solo, Campinas, v. 21, p. 105-112, 1997.

BAYER, C.; MIELNICZUK, J. Dinâmica e função da matéria orgânica. In: SANTOS, G. de A.; CAMARGO, F. A. de O. (Eds.). Fundamentos da matéria orgânica do solo: ecossitemas tropicais e subtropicais. Porto Alegre: Gênesis, 1999. cap. 2, p. 9-26.

BAYER, C.; MIELNICZUK, J.; MARTIN-NETO, L. Efeito de sistemas de preparo e de cultura na dinâmica da matéria orgânica e na mitigação das emissões de $\mathrm{CO}_{2}$. Revista Brasileira de Ciência do Solo, Viçosa, v. 24, n. 3, p. 599-607, jul./set. 2000a.

BAYER, C.; MIELNICZUK, J.; MARTIN-NETO, L.; CERETTA, C. A. Effect of on no till ropping systems on soil organic matter in an sandy clay loan Acrisol from southern Brazil monitored by electron spin resonance and nuclear magnetic resonance of 13 C. Soil Tillage, Amsterdam, v. 53, p. 95-104, 2000 b.
BURLE, M. L.; MIELNICZUK, J.; FOCCHI, S. Effect of cropping systems on soil chemical characteristics, with emphasis on soil acidification. Plant and Soil, The Hague, v. 190, p. 309-316, 1997.

CASTRO FILHO, C.; VIEIRA, M. J.; CASÃO JÚNIOR, R. Tillage methods and soil and water conservation in southern Brazil. Soil Tillage, Amsterdam, v. 20, p. 271-283, 1991.

CORAZZA, E. J.; SILVA, J. E.; RESCK, D. V. S.; GOMES, A. C. Comportamento de diferentes sistemas de manejo como fonte de depósito de carbono em relação à vegetação de cerrado. Revista Brasileira de Ciência do Solo, Viçosa, v. 23, n. 2, p. 425-432, abr./jun. 1999.

D’ANDRÉA, A. F. Atributos indicadores da qualidade do solo em sistemas de manejo no Sul de Goiás. 2001. 106 p. Dissertação (Mestrado em Solos e Nutrição de Plantas) - Universidade Federal de Lavras, Lavras, 2001.

DAY, P. R. Particle fractionation and particle-size analysis. In: BLACK, C. A. Methods of soil analysis. Madison: American Society of Agronomy, 1965. v. 1, p. $545-566$.

EMPRESA BRASILEIRA DE PESQUISA AGROPECUÁRIA. Manual de métodos de análises de solo. Rio de Janeiro: Ministério da Agricultura, 1997. Não paginado.

FERREIRA, D. F. Análises estatísticas por meio do SISVAR (Sistema par Análise de Variância) para Windows: versão 4.0. In: REUNIÃO ANUAL DA REGIÃO DA BRASILEIRA DA SOCIEDADE INTERNACIONAL DE BIOMETRIA, 45., 2000, São Carlos. Anais... São Carlos: UFSCar, 2000. p. 255-258.

FORTIN, M. C.; ROCHETTE, P.; PATTEY, E. Soil carbon dioxide fluxes from conventional and notillage small-grain cropping systems. Soil Science Society America Journal, Madison, v. 60, p. 15411547, 1996.

FREITAS, P. L.; BLANCANEAUX, P.; GAVINELLI, E.; LARRÉ-LARROUY, M.; FELLER, C. Nível e natureza do estoque orgânico de Latossolos sob diferentes sistemas de uso e manejo. Pesquisa Agropecuária Brasileira, Brasília, v. 35, n. 1, p. 157-170, jan. 2000. 
FREIXO, A. A.; MACHADO, P. L. O. A.; GUIMARÃES, C. M.; SILVA, C. A.; FADIGAS, F. S. Estoque de carbono e nitrogênio e distribuição de frações orgânicas de Latossolo do cerrado sob diferentes sistemas de cultivo. Revista Brasileira de Ciência do Solo, Viçosa, v. 26, n. 2, p. 425-434, 2002.

GREENLAND, D. J. Change in the nitrogen status and physical condition of soils under pastures, with special reference to the maintenance of the fertility of Australian soils used for growing wheat. Soil and Fertilizers, Berlin, v. 34, p. 237-251, 1971.

NEVES, C. M. N. Atributos indicadores da qualidade do solo em sistema agrossilvopastoril, no noroeste do estado de Minas Gerais. 2002. 87 p. Dissertação (Mestrado em Solos e Nutrição de Plantas) - Universidade Federal de Lavras, Lavras, 2002.

ROCHA, M. T. Aquecimento e o seqüestro de carbono em projetos agroflorestais. Revista Ecologia, Rio de Janeiro, n. 151, 2000.
SAS INSTITUTE. SAS user's guide: statistics. 5. ed. Cary, 1985. 956 p.

SILVA, R. R. Qualidade do solo em função de diferentes sistemas de manejo na região Campos das Vertentes, Bacia Alto Rio Grande - MG. 2001. 97 p. Dissertação (Mestrado em Solos e Nutrição de Plantas) - Universidade Federal de Lavras, Lavras, 2001.

TOKURA, A. M.; FURTINI NETO, A. E.; CURI, N.; FAQUIN, V.; KURIHARA, C. H.; ALOVISI, A. A. Formas de fósforo em solo sob plantio direto em razão da profundidade e tempo de cultivo. Pesquisa Agropecuária Brasileira, Brasília, v. 37, n. 10, p. 1467-1476, out. 2002.

WALKLEY, A.; BLACK, I. A. An examination of the Degtjareff method for determining soil organic matter and a proposed modification of the chromic acid titration method. Soil Science, Baltimore, v. 37, n. 1, p. 29-38, Jan./June 1934. 